\title{
UNA ODISEA EN NUESTRA ÉPOCA
}

\author{
AN ODYSSEY IN OUR EPOCH
}

Santiago Jiménez de la Torre

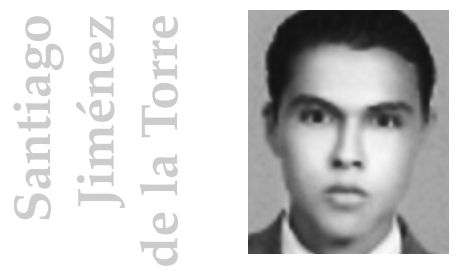

Estudiante de Pedagogía, Facultad de Filosofía y Ciencias Sociales, Universidad Panamericana. Profesor de Moral, Centro Escolar Cedros, México.

Correo electrónico: [0150823@up.edu.mx].

\section{DISERTACIONES SOBRE LA AUTORIDAD}

El mismo dinamismo del lenguaje complica las cosas a la hora de definir un concepto, sobre todo cuando aquél posee, en mayor o menor medida, algún alcance filosófico; es decir, no es lo mismo definir «sombrero» que «amor»: mientras más implique al hombre mismo, más ardua se vuelve la labor de conceptualización. Autoridad es justamente uno de estos difíciles casos; sin embargo, aun con todas estas dificultades, seguiremos a Rafael del Águila ${ }^{1}$ para dar una bien acogida definición. Autoridad, es «el ejercicio institucionalizado del poder» ${ }^{2}$. Vemos, entonces, uno de los obstáculos con los que la conceptualización de autoridad se enfrenta: ¿qué diferencia existe entre autoridad y poder? El mismo Del Águila nos ayuda: «El poder es la posibilidad de obtener obediencia incluso contra la resistencia de los demás» ${ }^{3}$.

1 Rafael del Águila (1953-2009) fue un reconocido catedrático de Ciencias Políticas en la Universidad Autónoma de Madrid.

2 Rafael del Águila, Manual de Ciencia Política, p. 21.

3 Ibid., p. 24. 
Pensadores de todos los tiempos no logran poner fin a la discusión de si el poder se relaciona con coacción o no, de si autoridad se relaciona con ejemplaridad o no. Pero para efectos de nuestro análisis, no interesa demasiado saber a ciencia cierta cuál es la diferencia entre autoridad y poder, entre otras cosas porque esa concepción atiende más a la política que a la familia, institución objeto de nuestro análisis.

De todos modos, no fueron inútiles los primeros acercamientos porque, dicho lo anterior, sabemos que quien ostenta legítimamente el poder, y, por lo tanto, tiene la autoridad necesaria en la familia, son los padres, nadie más. Si su autoridad sucumbe, la familia se quebranta ${ }^{4}$ y, peor todavía, la misma sociedad no podrá mirar la deslumbrante luz del progreso, y es que

[...] la familia posee vínculos vitales y orgánicos con la sociedad, porque constituye su fundamento y alimento continuo mediante su función de servicio a la vida. En efecto, de la familia nacen los ciudadanos, y estos encuentran en ella la primera escuela de esas virtudes sociales, que son el alma de la vida y del desarrollo de la sociedad misma ${ }^{5}$.

\section{LA LEY: UNA BATALLA POR ALCANZAR}

El Estado, a través de sus leyes, no parece colocarse al frente en la defensa de la familia. Hechos como la legislación del aborto, de la eutanasia, de la droga, de los matrimonios homosexuales, son algunas de las causas - y efectos- de la desvalorización de la familia, que ha venido manteniendo el Estado en las últimas décadas.

4 Este es el principal peligro de la pérdida de autoridad de los padres por sobre los hijos: sin importar el número de hijos, la familia, grande o pequeña, se va poco a poco hacia abajo, a tal grado que su decadencia es inevitable. Hoy en día, sabemos, la familia no es lo que era antes y una posible respuesta es que son los padres los «culpables», pues no se atreven a ejercer la autoridad propia a su naturaleza de padres, de procreadores.

5 Juan Pablo II, Familiaris consortio, n. 42. En: [https: / / mail.google.com / mail / ?ui=2\&ik=35506391f0\&view=att\&th=13076aae2264226 9\&attid=0.1\&disp=inline\&realattid=f_goqbk6pu0\&zw]. 
El argumento más usado por los «anti-familia» es el de que, al estar legalizadas todas las cuestiones anteriores, son completamente legítimas y lícitas. Pero, ¿solo por ser ley humana, se vuelve lícita y, por lo tanto, buena? Santo Tomás en su Suma Teológica afirma que la ley humana «[...] es la prescripción de la razón en orden al Bien Común, promulgada por quien tiene a su cargo el cuidado de la comunidad» ${ }^{6}$. Podemos concluir, sin temor a equivocarnos, que si una ley no proviene de la razón y no está ordenada al bien común, no es ley en ningún sentido. Queda derribado el endeble argumento de los legalistas.

Al momento de escuchar esas vocecillas que intentan por todos los medios asesinar a la familia - a la de padre, madre e hijos; a la que toma en cuenta la unidad y la procreación; a la que nos ha hecho posible soñar con un mundo sano y agradable para vivir...-, debemos preguntarnos, junto con Joseph Ratzinger:

¿Quién o qué legitima este mensaje? ¿Está lo suficientemente legitimado para parecernos plausible? ¿Basta la plausibilidad como criterio para aceptar un mensaje sobre Dios? ${ }^{7}$ ¿ ¿O es precisamente la plausibilidad una tentación que nos halaga?» ${ }^{8}$.

\section{SENDEROS CON FINES NOBLES: LA LIBERTAD}

Cuando los padres ejercen, también por su propia naturaleza, el papel de educadores -más aún: de primeros educadores- deben tener en cuenta que, si realmente desean hacerlo y serlo bien, tendrán que saber ejercer su autoridad. Pero, ¿para qué, para qué vale la pena ejercer la autoridad ${ }^{9}$ sobre los hijos? En definitiva, la respuesta más precisa es para que los hijos puedan ejercer correctamente su libertad. Aquí está el quid del asunto.

6 Sto. Tomás, S. Th., Ia, IIa, 90, 4.

7 Aunque Ratzinger habla en un contexto religioso, es evidente que en lugar de «Dios» se puede insertar «sobre la familia».

8 P. Seewald, Dios y el mundo: una conversación con Peter Seewald. Las opiniones de Benedicto XVI sobre los grandes temas de hoy, p. 65.

9 Ejercer la propia autoridad no significa ser autoritarios. De la autoridad al autoritarismo existe una gran diferencia. 
También aquí existe un peligro demasiado sutil —al menos así se ha mostrado a lo largo de la historia-: el de no saber qué es la libertad. Muchos han postulado la libertad como el hacer lo que en el momento más plazca - misma concepción que se acerca más al libertinaje: perversión, degeneración, depravación de la libertad-. Lo que sí sabemos certeramente es que

[...] la libertad está limitada por las características de nuestra naturaleza y por las circunstancias de nuestra existencia. [...] todo hombre tiene la capacidad de elegir lo que es mejor para él. Y eso es la libertad ${ }^{10}$.

Así pues, como conclusión, los padres, primeros educadores, deben ejercer su autoridad para poder educar confiablemente en y para la libertad a sus hijos. Así es la familia, así es su realidad, así es la explicación del cómo lograr un mejor futuro para nuestra sociedad, misma que es de memoria corta $\mathrm{y}$, por medio del deleznable individualismo, nos va engañando para conseguir su objetivo: la muerte de la familia, la supremacía del individuo. No hay salidas cobardes, no hay dulces placebos; solo nos queda luchar - en las trincheras de la inmediatez de lo ordinario- para conseguir la victoria en una Odisea de nuestra época. 


\section{REFERENCIAS BIBLIOGRÁFICAS}

DEL ÁGUILA, Rafael. Manual de ciencia política, Editorial Trotta, Madrid, 2009, $514 \mathrm{p}$.

JUAN PABLO II. Exhortación apostólica Familaris consortio, 1981. En:

[http:/ / www.vatican.va/holy_father/john_paul_ii/apost_exhortations/documents/hf_jp-ii_exh_19811122_familiarisconsortio_sp.html].

MALMIERCA, Almudena. Al llegar la juventud, Minos, Colección Ser Familia, México, 1992, 291 p.

SEEWALD, Peter. Dios y el mundo: Una conversación con Peter Seewald. Las opiniones de Benedicto XVI sobre los grandes temas de hoy, Debolsillo, Barcelona, 2005, 448 p.

SANTO TOMÁS. Suma Teológica, Biblioteca de Autores Cristianos, Barcelona, 2010, XVI tomos. 